\title{
ABORDAGENS DAS COMPETÊNCIAS SOCIOEMOCIONAIS SOB ENFOQUE LEGAL E APLICAÇÃO NO ENSINO SUPERIOR
}

\section{ARTIGO ORIGINAL}

VANTROBA, Edevana Leonor ${ }^{1}$

VANTROBA, Edevana Leonor. Abordagens das competências socioemocionais sob enfoque legal e aplicação no Ensino Superior. Revista Científica Multidisciplinar Núcleo do Conhecimento. Ano 05, Ed. 06, Vol. 11, pp. 89-101. Junho de 2020. ISSN: 2448-0959, Link de acesso:

\section{https://www.nucleodoconhecimento.com.br/educacao/aplicacao-no-ensino}

\section{RESUMO}

As competências socioemocionais enfatizam o domínio e desenvolvimento de habilidades não inatas direcionadas ao trabalho, características adquiridas no processo de interação familiar, educacional e profissional. Sua aquisição permite o desenvolvimento pessoal, o exercício da cidadania, a inclusão social, a inserção profissional e a aprendizagem continuada. Aborda aspectos conceituais que define e enfoca contextos legais, demarca os destaques da sua aplicação, incluindo componentes como o aprendizado, o recrutamento realizado pelas empresas. Destaca o valor do educador e sua participação ativa na qualificação dos professores e nas melhorias socioemocionais dos estudantes. Retrata o trabalho no ensino superior, ponderando sobre regulação emocional, motivação, experiência, projetos, trabalho dos educadores, mentoria e compartilhamento, envolvimento dos gestores e

1 Possui graduação em Curso de Pedagogia com Administração Escolar pela Faculdade de Filosofia, Ciências e Letras de Itararé (2003) e graduação em Licenciatura Plena em Letras pela Faculdade de Filosofia, Ciências e Letras de Itapetininga (1996). Atualmente é e professor ensino médio/técnico do Centro Estadual de Educação Tecnológica Paula Souza. Tem especialização na área de Letras, com ênfase em Língua Portuguesa e Psicopedagogia. 
da comunidade institucional, integrando as competências socioemocionais, às competências profissionais desenvolvidas na educação superior.

Palavras-Chave: Competência, contexto legal, aprendizagem, habilidades, qualificação.

\section{INTRODUÇÃO}

\subsection{CONTEXTO DAS COMPETÊNCIAS SOCIOEMOCIONAIS SOB ENFOQUE LEGAL}

O conceito de competências socioemocionais envolve a compreensão das emoções, as quais ao longo da história foram abordadas de diferentes perspectivas: da psicopedagogia e psicologia, da biologia, dos padrões das espécies e da cultura etc.

Wallon (2016), contribui com informações para se pensar no desenvolvimento humano em todas as suas instâncias seja biológica, psíquica ou social, propondo um modelo de desenvolvimento que unifica as dimensões do ato motor, da afetividade e da inteligência do ser humano, que nos embasa na reflexão de diferentes aspectos inerentes à integração entre as habilidades cognitivas e socioemocionais. (ABED, 2014)

Em novembro de 2015, o relatório Competências para o progresso social: o poder das competências socioemocionais, lançado oficialmente pela OCDE, (Casel, Wida, Center for Curriculum Redesign, MEC) durante o $1^{\text { }}$ Seminário do núcleo de pesquisas criado em 2014 objetivou construir uma avaliação brasileira capaz de medir as habilidades socioemocionais dos estudantes. O evento idealizado pelo Instituto Ayrton Senna (IAS), Insper e Universidade de Ghent (Bélgica), professores universitários do Brasil e dos Estados Unidos e representantes das secretarias estaduais de educação de São Paulo, Rio de Janeiro e Ceará também integram o projeto. Existem diferentes estudos e práticas internacionais e nacionais voltadas a esse trabalho, diferentes avaliações de grande escala abordam essas competências, como o PISA (Programme for International Student Assessment) e o ENEM (Exame Nacional do Ensino Médio). 
A Teoria dos Big Five organiza as competências em cinco dimensões: Abertura a Novas Experiências (estéticas, culturais, intelectuais), Conscienciosidade (organização, esforço, responsabilidade), Extroversão (interesses e energia do mundo externo, pessoas e coisas), Amabilidade (ação de modo cooperativo), Estabilidade Emocional (previsibilidade e consistência de reações emocionais).

Os Parceiros para Habilidades do Século XXI (Partners for 21st Century Skills) uma coalizão surgida nos Estados Unidos relaciona uma série de competências para que os jovens sejam bem sucedidos na universidade, como as Habilidades para o Aprendizado e para Inovação (criatividade, pensamento crítico, resolução de problemas, comunicação, colaboração), e para Vida e Carreira (flexibilidade e adaptabilidade, iniciativa e autonomia, habilidades sociais e interculturais, capacidade de assumir compromissos, liderança e responsabilidade). Temos ainda o Centro de Referências em Educação Integral que produziu referências curriculares que listam competências relacionadas ao Desenvolvimento Emocional, o Inspirare que realiza uma Série de Diálogos sobre o tema, Porvir em parceria com o Instituto Ayrton Senna, o que reforça e enfatiza a real importância e os impactos positivos diante da articulação de diversos agentes.

No contexto escolar brasileiro, a proposta de Educação para o século XXI é contemplada na proposta da BNCC (Base Nacional Comum Curricular) a qual orienta que os currículos das escolas da rede pública ou privada até 2020, estivessem preparados para novas regras, apresenta conhecimentos primordiais, competências e habilidades almejadas em etapas correspondentes.

O documento oficial norteia a construção de um currículo pedagógico, que aborde a realidade social, regional e metodológica de cada instituição de ensino.

Essa diretriz visa formar cidadãos capazes de resolver problemas, trabalhar em equipe, argumentar, defender, elucidar a criticidade e o ponto de vista, respeitar o outro, articulando o convívio e a flexibilidade na atualidade. 
$\mathrm{Na}$ BNCC, são dez as competências gerais, pesquisas chegaram a dezesseis principais capacidades socioemocionais, habilitadas de ser medidas e estimuladas, entre elas estão engajamento social, assertividade, entusiasmo, tolerância à frustração e criatividade, curiosidade, respeito, autoconfiança. Todas elas impulsionam as habilidades cognitivas e melhoram realidades sociais distintas, ao influenciarem o comportamento e o estilo de vida das pessoas. A perspectiva é que os professores possam direcionar dados para trabalhar com evasão e com o bullying, que compreende o conjunto de ações violentas e intencionais (geralmente repetidas) contra outra pessoa e que tem como produto danos que variam desde a ordem física à psicológica, deixando "marcas" que se prolongam durante a vida da pessoa que foi alvo. No combate ao bullying a autoconsciência, autogestão, consciência social, relacional e tomada de decisão responsável devem ser trabalhadas.

É imprescindível compreender que trata-se de competências não cognitivas e sim habilidades que precisam ser desenvolvidas no indivíduo, que em alguns profissionais e cidadãos que não aprenderam as competências socioemocionais dentro de uma metodologia adequada, o seu desenvolvimento possa ou não ocorrer nas experiências vividas por estes.

\section{DESENVOLVIMENTO}

\subsection{DESTAQUES DA APLICAÇÃO DA EDUCAÇÃO SOCIOEMOCIONAL}

Diante desse novo cenário, o aprendizado socioemocional deve permanecer durante toda a vida escolar e acadêmica dos alunos, as instituições de ensino devem transpor os conteúdos pedagógicos, ensinando os estudantes a criar finalidades para sua própria vida, se relacionar, trabalhar em equipe, lidar com valores e opiniões divergentes, acrescendo-se de habilidades emocionais como: construção de relacionamentos de Confiança e Respeito; Autoconfiança; Autoconhecimento; Controle das Emoções, fatores que contribuem para atingir suas metas pessoais, no trabalho, na universidade ou em situações cotidianas. 
Empresas aplicam etapas para analisar os candidatos no recrutamento e seleção, propondo atividades em grupo que incentivam o senso de cooperação, liderança e capacidade de enfrentar frustrações a partir de opiniões diferentes, ampliando habilidades de relacionamento. É muito comum que profissionais sem apelo socioemocional sejam demitidos, mesmo contratados por demonstrarem competências cognitivas, portanto, o pensamento autônomo dos estudantes deve ser estimulado com a promoção da educação das emoções, fundamental para evidenciar potencialidades que podem reduzir a indisciplina e melhorar os índices de aprendizado.

Alguns testes envolvem dilemas éticos exigindo posicionamento e reflexão na tomada de decisões, contribuindo para o pensamento crítico e autoconhecimento.

Outros focam na solução de problemas da vida profissional que envolve várias outras competências como a empatia, resiliência, criatividade e persistência.

Simulações de ocasiões da rotina profissional incentivam a superar adversidades e contribuem para a inteligência emocional, além da capacidade de liderança e segurança em contornar situações difíceis.

Conforme Daniel Goleman (1995, p.73), uma das maiores autoridades desse assunto, a inteligência emocional pode ser classificada em cinco habilidades complementares:

Autoconhecimento emocional: auxilia na imposição de limites e no poder de decisão em momentos cruciais;

Força mental: é o principal quesito para desenvolver as habilidades exigidas para usufruir dos benefícios da inteligência emocional;

Automotivação: um ideal que mantém a pessoa ávida pela realização de seus sonhos e objetivos;

Empatia: virtude necessária ao bom convívio pessoal, social e profissional; 
Habilidades sociais: perceber as necessidades dos outros é fundamental para melhorar os relacionamentos interpessoais.

Apenas conteúdos curriculares não parecem mais agradar a sociedade atual, o aprendizado e o controle socioemocional edifica relações respeitosas e construtivas que integrem o momento e o contexto social.

\subsection{O VALOR DO EDUCADOR E DE SUA PARTICIPAÇÃO ATIVA PARA MELHORIAS SOCIOEMOCIONAIS}

Para não dissociar aspectos da educação, é preciso garantir a integralidade ao trabalho executado com as socioemocionais, papéis exercidos por toda a sociedade, políticas públicas, psicólogos e psicopedagogos, comunidade escolar (família, diretores, coordenadores, professores...) para que as competências se desenvolvam dentro e fora da escola, norteando ações e objetivos alinhados com clareza, coerência, flexibilidade, focando no potencial do aluno com o cuidado de incorrer no erro de salientar suas dificuldades durante o processo.

A qualificação didática dos educadores precisa dispor de projetos executados por profissionais especializados em desenvolvimento pessoal, aptos a estimular e treinar educadores neste aprendizado, visando a apropriação do autocontrole emocional e motivacional, pois somente aqueles que possuem inteligência interpessoal, conseguirão prevenir, filtrar e direcionar significativamente boa parte das percepções psicológicas identificadas.

Isso se aplica igualmente ao professor do ensino superior, principalmente os que formarão novos docentes e necessitam estar qualificados para atender esse público de profissionais devem realizar com destreza a preparação e execução das aulas englobando as competências socioemocionais, que mereceram destaque após o reconhecimento de que características ligadas ao comportamento e à administração das próprias emoções impactam de maneira positiva na aprendizagem e influenciam na vida como um todo. 
O ensino de competências socioemocionais se deu em razão da compreensibilidade das características da personalidade e clareza de utilizá-las como temas a serem desenvolvimentos com os alunos.

Segundo Santos $(2014$, p.7):

a) Conscienciosidade: propensão a ser organizado, responsável e esforçado.

b) Abertura a novas experiências (domínio que abrange também o intelecto): propensão a aceitar novas experiências estéticas, culturais ou intelectuais.

c) Estabilidade emocional (neuroticismo): previsibilidade e consistência de reações emocionais (estabilidade emocional); propensão ao desequilíbrio psicológico (neuroticismo).

d) Extroversão: Direcionamento de interesses e energia em direção ao mundo externo de pessoas e coisas (ao invés do mundo interno de experiências subjetivas). Caracterizado pela afetividade e sociabilidade.

e) Amabilidade: propensão a agir de modo cooperativo e não egoísta.

No atual cenário da saúde mental dos professores que além de passar por muita pressão cotidiana, contam com a desvalorização de suas carreiras pela sociedade e pelo poder público que reflete em baixa autoestima para a classe, considerada uma das profissões mais estressantes do mundo, fica a pergunta de como treinar o aluno para se controlar se quem aplica esses conceitos não as possuir.

Dados reais comprovam que grande maioria dos educadores não detém as competências socioemocionais em si mesmos, o que não será resolvido com simples estudos teóricos sobre o tema, recomenda-se que o docente planeje e vivencie atividades provocadoras, que leve a reflexão de sua própria gestão das emoções no relacionamento com os outros e expansão da consciência. 
Para guiar alguém é preciso primeiro percorrer e conhecer o caminho, quando se fala em capacitar um educador, é indispensável que tenha adquirido para si mesmo essas competências, para depois ensiná-las.

Publicações e pesquisas diversas demonstram que no Brasil, grande percentual de professores enfrenta algum tipo de confusão psicológica, são comuns crises de estafa e ansiedade, estresse, depressão, síndrome de Burnout e problemas nos relacionamentos.

Atualmente, existem no mercado brasileiro alguns programas e treinamentos especializados, voltados para o educador que prevê a competência socioemocional como um viés a ser elucidado para possíveis prevenções de sintomas preparando e tratando esse profissional para o árduo trabalho de formar todas as profissões, assim como um final de carreira digno e respeitoso àqueles que tanto contribuíram para a evolução do aluno em toda sua trajetória educacional, além de contribuir para os moldes mundiais da educação, que abrangem e referenciam como um pilar fundamental o desenvolvimento socioemocional.

\subsection{ONSINO SUPERIOR E O TRABALHO DA EDUCAÇÃO SOCIOEMOCIONAL}

Nessa tendência, colocar a educação socioemocional em prática é o novo desafio, a formação universitária desenvolve competências para o melhor ajustamento pessoaambiente, gestores e educadores precisam fortalecer os jovens a enfrentar as adversidades da vida acadêmica, do mercado de serviços e para formar profissionais com as aptidões necessárias para o sucesso, sempre associado aos aspectos humanos.

A aprendizagem nos moldes do adulto (Jarvis, 2005, p.17):

Mais pertinente à aprendizagem em contextos universitários, a prática, entendida como ação, e a emoção são centrais. Ainda que a aprendizagem planejada seja importante no processo de formação 
educacional e de preparação para o exercício da profissão, quando se trata de adultos aprendizes, aspectos motivacionais e emocionais estão em destaque, especialmente no caso da aprendizagem acidental, que se refere a resultados não programados da aprendizagem, mas que sempre a acompanham, tais como mudanças com relação à autopercepção, autoeficácia, autoestima e autoconfiança. Esses aspectos motivacionais e emocionais estão na base da automotivação, são fundamentais ao processo de aprendizagem contínua e aquisição de novas competências profissionais.

Sabemos que o conhecimento de mundo é adquirido pelos órgãos de sentido e pelas sensações, a visão, audição, o tato, o paladar, mas a experiência se alcança por vivências e por mediação da reflexão que permite o pensamento imediato.

O prazer ou desprazer e o modo de reflexão sobre suas experiências repercutem na autoconfiança e automotivação favorecendo a aprendizagem durante a formação universitária e início de carreira, então, estratégias e orientações pedagógicas exercem um importante papel na potencialização da experiência no processo de formação, preparando os discentes para refletir melhor sobre seu desempenho e a tornar-se mais autoconfiante no enfrentamento de suas futuras inserções de trabalho.

Cabe ainda, transversalizar a inclusão das competências de forma sistêmica e intencional, não somente através de ações isoladas, valorizando a continuidade para que não se resulte em algo inconsistente ou abstrato.

É possível estabelecer pactos de convivência no cotidiano, trabalhos em grupo e dinâmicas colaborativas, criação de espaços de discussão, reflexão e autoavaliação para contextualização de conhecimentos, conexão da realidade do aluno e do universo jovem com a universidade através de escuta qualificada que permite a argumentação dos mesmos.

Atividades práticas com supervisão docente e suporte aos mais adiantados no processo de formação são também instrumentos pedagógicos que permitem melhor 
aproveitamento da vivência no desenvolvimento de competências profissionais e atitudes favoráveis à aprendizagem continuada.

Outro fator é colocar-se no lugar do aluno, priorizar relações individualizadas e não massificadas, valorizando as potencialidades e tirando os discentes da invisibilidade, conhecendo seus hábitos e linguagens, diferenças geracionais, perpetuando sua identidade.

Ciclos de mentoria permitem aos docentes mais experientes que apoiem os que estão com dificuldade, discussões em redes sociais facilitam as trocas a distância admitindo inclusive parceiros externos de outras unidades no compartilhamento de experimentos e atitudes.

Os educadores não se devem deixar seduzir pelo seu poder sobre os alunos, sem autoritarismo, sem se envolver emocionalmente com eles, respeitar valores e estilos de cada um, com devolutivas e feedbacks mobilizadores que explicitem expectativas de aprendizagem.

Haja vista que a universidade e demais instâncias de formação profissional apresentam dificuldades em desenvolver no vasto ramo de trabalhos toda demanda de competências socioemocionais, os jovens necessitam tirar maior proveito da experiência dos primeiros anos de atividade profissional, e ainda inexperientes baseiam-se nos aprendizados da formação que são os primeiros com que tiveram contato, e somente depois de adquirirem a confiança necessária obtida pela prática aplicam sua aprendizagem; ajustando os saberes e fazeres adquiridos e capazes de analisá-los criticamente. (Benner, 1984, n.p).

Além da necessidade de seguir aprendendo em sua carreira profissional o jovem precisa estar entusiasmado e emocionalmente preparado para subjugar conflitos interpessoais presentes nas relações de trabalho.

Em revisões recentes Mazzola; Schonfeld, e Spector, apontam que estes ocupam a terceira posição entre as causas de estresse no trabalho, as primeiras são os conflitos 
e sobrecarga organizacionais, o que evidencia ainda mais o alerta para a adaptação e do bem estar funcional (Mazzola; Schonfeld, e Spector, 2011, n.p).

Pressupõe-se para (Bisquerra, 2009, p.197) serem cinco os componentes para a competência socioemocional:

1. Consciência emocional de si e de outras pessoas, incluindo a capacidade de captar o clima emocional em um contexto específico.

2. Regulação emocional, refere-se ao gerenciamento apropriado das emoções, cujos aspectos cognitivos são fundamentais na busca de estratégias de enfrentamento que potencializem as emoções positivas e minimizem as negativas.

3. Autonomia emocional, destaca a atitude positiva em relação a si mesmo e a vida, mantendo a autoestima elevada e reconhecendo os limites pessoais, recorrendo, em caso de necessidade, à ajuda externa.

4. Domínio de habilidades sociais, destacando o atributo de se comunicar, ser assertivo e adotar atitudes respeitosas para com as demais pessoas.

5. Habilidades de vida e bem-estar, definidas como a aptidão de adotar comportamentos apropriados e responsáveis para solucionar problemas pessoais, familiares, profissionais e sociais, preservando o contentamento pessoal e social.

Diante de duas perspectivas, uma mais focada no desempenho no trabalho (Boyatzis, 2009 , n. p) e a outra apoiada no princípio do desenvolvimento humano integral (Bisquerra, 2009), ambas contemplam aspectos fundamentais das competências socioemocionais, e exige articular e mediar os recursos pessoais e ambientais, tanto no processo quanto no resultado. 
Definidos como ciclo ERAT (ambiente no qual a aprendizagem e a consciência pessoal emergem de sentimentos e emoções afloradas, acompanhados a novos contextos da criatividade emocional, favorecem a autorreflexão e a aplicação prática sobre o sentir, e experimentar coisas novas.

No trato com a vida, a competência socioemocional recai favoravelmente em uma sequência de eventos que incluem experimentar, refletir, aplicar e transferir os conhecimentos, as habilidades e os sentimentos adquiridos, implicando na consciência e regulação emocional como social.

$\mathrm{Na}$ consciência de suas próprias emoções o jovem é incentivado a expressá-las e as utilizar na prática, oferecendo suporte ao controle dessas emoções frente a sucessos ou fracassos, criando possibilidades de potencializar as emoções positivas e reduzir as emoções negativas, através de estratégias adaptativas e funcionais.

O trabalho com projetos e incentivo à pesquisa com temas relevantes, interdisciplinares potencializam a mediação do professor, a articulação das disciplinas, contribuem para integração e valorizam práticas de colaboração com atividades mais conectadas orientando projeto de vida, mercado profissional e intervenções sociais ou comunitárias no entorno da universidade permitindo ao aluno aprender a esclarecer questões reais enquanto desenvolve o trabalho prático.

O termo inglês VUCA (Volatilidade, Incerteza, Complexidade e Ambiguidade) em constante evolução e inovação, demanda um investimento nas habilidades socioemocionais e sua aplicação no ensino superior ,colocá-las em prática com algumas estratégias pedagógicas focadas em situações de aprendizagem que ofereçam suporte para que usem suas habilidades sociais em um ambiente seguro, ampliando suas condições de bons relacionamentos.

Análise de dilemas éticos: na qual o educador apresenta questionamentos aos alunos, pedindo que se posicionem a respeito.

Quando deparados com situações desconfortáveis, refletem antes de se posicionarem e tomarem as decisões, evidencia o pensamento crítico e o autoconhecimento. 
Resolução de problemas da vida profissional: envolve várias outras habilidades, como resiliência, criatividade e persistência. Ocasiões rotineiras podem ser simuladas prevendo superação de tribulações, corroborando para a inteligência emocional, capacidade de liderança e a segurança para consolidar casos habituais sem receio.

Ao gestores cabe assegurar que a instituição tenha instalações confortáveis e agradáveis, que facilitem as relações humanas, biblioteca, boa conectividade à internet e banda larga, que possam ser usados de forma flexível, dispor de materiais pedagógicos, fortalecer a comunicação interna e externa, permitir eventos mobilizadores que envolvam a comunidade, alunos egressos com depoimentos, trabalho voluntário, jogos, enfim engajamento de professores, alunos e funcionários como atores responsáveis pelas demandas surgidas.

Construir um discurso comum garantindo a coesão das ações e equipes valorizando a gestão democrática, assegurando o exercício do diálogo efetivo, abrindo portas para famílias e comunidades interagirem na universidade.

Descentralizar quando necessário, delegando funções com responsabilidade e comprometimento de seus pares e de todos os envolvidos.

\subsection{RESULTADOS ESPERADOS}

Feedbacks relevantes capazes de orientar progressos e falhas, oferecem evidências capazes de fazer perceber a importância do trabalho.

O acompanhamento dos trabalhos permite mensurar o impacto na vida de todos os atores envolvidos.

Oferece dados para que se possam estabelecer prioridades e identificar caminhos para melhoria de sua prática.

Fatos advindos destas análises ajudam a personalizar melhor o trabalho na instituição e saber se estão funcionando, bem como utilizar instrumentos que conjuguem a autoavaliação do aluno e a avaliação do professor também é pertinente, o processo 
deve respeitar as três fases: diagnóstico, análise e devolutiva, vincular tecnologias para o acompanhamento e monitoramento, uso de instrumentos para avaliar o impacto dos materiais existentes e gerar referência para a aplicação de tecnologias assertivas e desenvolvimento de recursos pedagógicos adaptados.

Grupos situacionais podem ser criados, assim como rodas da conversa para discussão promovendo a fala e escuta de todos os agentes envolvidos, estímulo contínuo à participação, análise e reflexão dos temas abordados, abertura à diversidade, ao debate a cultura local e a aplicação de valorosas contribuições.

Oportunizando o acesso e interatividade, fomentar novas formas de aprendizagem e a produção de conteúdos digitais pelos próprios alunos, videoconferências para otimizar a visão global e as trocas culturais.

Inserção de iniciativas que promovam a competências socioemocionais em programas e diretrizes governamentais.

Trabalhar o contexto histórico e cultural da comunidade, mapeando exemplos positivos e experiências inspiradoras em seu entorno.

A definição clara, a explicitação dos resultados esperados e a flexibilidade para acolher situações ou elementos emergentes viabiliza a aderência aos objetivos institucionais e a solucionar desafios que quando superados merecem ser compartilhados com a merecida celebração das conquistas.

Como defende Goleman (1995), é o desenvolvimento da cognição, da afeição e de comportamentos para promover a formação total do indivíduo.

\section{CONSIDERAÇÕES FINAIS}

Formar cidadãos socialmente responsáveis é uma preocupação cada vez maior, disposto a compreender e perceber seu papel no mundo, disposto a desenvolver-se pessoal e profissionalmente. Para que isso ocorra de forma natural é preciso que 
saibam trabalhar com emoções, metas e relações sociais durante o cotidiano e por toda a vida.

Nestas circunstâncias as competências não cognitivas ou socioemocionais, figuram na função definitiva de desenvolver a formação intelectual de um indivíduo, e possuir essas habilidades denota estar preparado plenamente para aprender mais e melhor.

Nos pressupostos aqui apresentados, podemos concluir que fica para os educadores o impasse de alinhar as práticas de sala de aula (dentro e fora dela) além da certeza de que as mudanças que forem alcançadas promoverão um clima empático e respeitoso além de auxiliar no desempenho acadêmico e cognitivo dos alunos, e nos impactos da sua convivência em sociedade.

A constituição das competências socioemocionais integra saberes apoiados na consciência, na expressão, na regulação e na administração das emoções, que considera melhorar o bem-estar pessoal por completo assim como a qualidade das relações sociais.

Outro fator preponderante é a reflexão sobre a vivência e experiência direta , maneira pela qual as competências profissionais são desenvolvidas, geralmente potencializadas durante o período universitário que é um processo de formação para o jovem que precisa se envolver num processo de aprendizagem contínuo, que lhe proporciona os benefícios da experiência e exercem vital importância na construção bem-sucedida de sua trajetória profissional.

No amparo legal destaque para a BNCC (Base Nacional Comum Curricular) um documento atual que aborda e vislumbra a educação de qualidade, orienta os currículos escolares visando garantir os direitos de aprendizagens mínimas que os estudantes devem possuir, orienta a composição das propostas pedagógicas, promovendo o desenvolvimento social buscando a qualidade da educação do Brasil. 


\section{REFERÊNCIAS}

ABED, Anita. O desenvolvimento das habilidades socioemocionais como caminho para a aprendizagem e o sucesso escolar de alunos da educação básica. São Paulo: UNESCO/MEC, 2014.

BAZZO, W. A.; VON L. I.; PEREIRA, L. T. V. (Eds.). Introdução aos Estudos Ciência, Tecnologia e Sociedade - CTS, Madrid: OEI, 2003.

BISQUERRA, R. (2003). Educación emocional y competencias básicas para la vida. Revista de Investigacion Educativa (RIE). 21 (1.7-43.).

BISQUERRA, R. (2009). Psicopedagogía de las emociones. Madrid: Síntesis.

BOYATZIS, R.E. (2009). Competencies as a behavioural approach to emotional intelligence. Journal of Management Development. 28.9;749-770.

BRASIL. Base Nacional Comum Curricular: Ensino Médio. Brasília: MEC/Secretaria de Educação Básica, 2018. Acesso em agosto de 2019

CASEL (2017). Competência socioemocional: conceitos e instrumentos associados. Publicação de Collaborative for Academic, Social, and Emotional Learning. Framework for systemic social and emotional learning. Retrieved from http://www.casel.org/what-is-sel. Acesso em fevereiro de 2020.

CONSELHO NACIONAL DE EDUCAÇÃO (Brasil). Conselho Pleno. Diretrizes curriculares nacionais gerais para a organização e o funcionamento dos cursos superiores de tecnologia. Brasília, DF, 2002. Inclui Parecer CNE/CP № 29/2002 e Resolução CNE/CP no 03/2002.

CORDÃO, F. A. Desafios das diretrizes curriculares nacionais para a educação profissional. Boletim Técnico do Senac, Rio de Janeiro, v. 39, n. 2, p. 26-47, maio/ago. 2013.

CORDÃO, F. A. Entrevista. Aprendizagem, Pinhais, n. 28, jan./fev. 2012b. 
DELORS, Jacques et al. Relatório para a UNESCO da Comissão Internacional sobre Educação para o Século XXI: educação: um tesouro a descobrir. [Genebra]: UNESCO, 1996.

FREIRE, P. Pedagogia da autonomia: saberes necessários à prática educativa. São Paulo: Editora Paz e Terra, 2003.

FRIGOTTO, G. (org). Educação e crise do trabalho: perspectivas de final de século. 7 ed. Petrópolis, RJ: Vozes, 2005.

GOLEMAN, Daniel. Inteligência Emocional. 65. Rio de Janeiro: Objetiva. 1995

GLOBAL Education Leaders' Program Brasil. Habilidades-socioemocionais-questõesconceituais-e-práticas. Disponível: http://fundacaotelefonica.org.br/acervo/ Acesso ago.2019

JARVIS, M. The psychology of effective learning and teaching. Cheltenham, Nelson Thornes, não paginada. 2005.

MENEZES, D. Competência socioemocional para o trabalho: princípio educativo a partir dos planos de marketing. Aracaju: Criação, 2019.

OLIVER, J. (1990). A taxonomia do fator "Big Five": Dimensões da personalidade na linguagem natural e nos questionários. Em LA Pervin (Ed.), Manual de personalidade: Teoria e pesquisa (pp. 66-100). Nova York, NY, EUA: The Guilford Press. Acesso em janeiro de 2018.

OCDE (2015), Habilidades para o progresso social: o poder das habilidades sociais e emocionais, Publicação da OCDE, Paris, https://dx.doi.org/10.1787/9789264226159en. Acesso fevereiro de 2020.

ONU (2015). Organização das Nações Unidas - Agenda 2030. Disponível em: https://nacoesunidas.org/pos2015/agenda2030/. Acesso em julho de 2016. 
SANTOS, Daniel. A importância socioeconômica das características de

Personalidade. Instituto Airton Senna. São Paulo: 2014.

Enviado: Junho, 2020.

Aprovado: Junho, 2020. 